\title{
Characteristics of episodic breathlessness as reported by patients with advanced chronic obstructive pulmonary disease and lung cancer: Results of a descriptive cohort study
}

Palliative Medicine

2015, Vol. 29(5) 420-428

(C) The Author(s) 2015

Reprints and permissions:

sagepub.co.uk/journalsPermissions.nav DOI: $10.1177 / 0269216314563428$

pmj.sagepub.com

@SAGE

\author{
Vera Weingärtner ${ }^{1,2}$, Christine Scheve ${ }^{2,3}$, Verena Gerdes ${ }^{2}$, Michael Schwarz- \\ Eywill $^{3}$, Regina Prenzel ${ }^{4}$, Burkhard Otremba ${ }^{5}$, Juliane Mühlenbrock ${ }^{3}$, \\ Claudia Bausewein 2,6, Irene J Higginson? ${ }^{7}$ Raymond Voltz ${ }^{1,8,9}$, Lena Herich ${ }^{10}$, \\ Steffen T Simon ${ }^{1,2,8,9}$; on behalf of PAALiativ
}

\begin{abstract}
Background: Episodic breathlessness is one form of refractory breathlessness. Better understanding of the symptom is necessary for effective management.

Aim: The aim was to describe the characteristics of episodic breathlessness in patients with advanced chronic obstructive pulmonary disease or lung cancer.

Design: This is a longitudinal cohort study. Outcomes were assessed monthly by up to 13 telephone interviews: peak severity (modified Borg scale: 0-10), duration, frequency, and timing of breathlessness episodes. Data from each episode were pooled and analyzed using descriptive statistics. Associations between outcomes were explored by correlation coefficients.

Setting/participants: Patients with chronic obstructive pulmonary disease (Global Initiative for Chronic Obstructive Lung Disease classification stage III or IV) or primary lung cancer (any stage) were recruited in two inpatient units (internal medicine) and two outpatient clinics in Oldenburg, Germany.

Results: A total of 82 patients (50 chronic obstructive pulmonary disease, 32 lung cancer), mean age (standard deviation) 67years (8years) and $36 \%$ female, were included reporting on 592 breathlessness episodes (chronic obstructive pulmonary disease: 403, lung cancer: 189). Peak severity was perceived significantly higher in chronic obstructive pulmonary disease patients than in lung cancer patients (mean (standard deviation) Borg scale: 6.2 (2.I) vs 4.2 (I.9); $p<0.00 \mathrm{I})$. Episodes described by chronic obstructive pulmonary disease patients were longer than those described by lung cancer patients (median (range): $7 \mathrm{~min}(0-600)$ vs $5 \mathrm{~min}(0.3-120), p=0.002)$ ). Frequency was similar and most often daily in both groups. Severity and frequency of episodes were correlated in lung cancer patients $(r=0.324, p=0.009)$. Conclusion: Most breathlessness episodes are short (minutes) and severe with significant differences between chronic obstructive pulmonary disease and lung cancer patients. Effective management strategies are warranted to improve symptom relief and coping.
\end{abstract}

\section{Keywords}

Chronic obstructive pulmonary disease, cohort studies, dyspnea, episodic breathlessness, lung neoplasms, palliative care

\footnotetext{
'Department of Palliative Medicine, University Hospital of Cologne, Cologne, Germany

2Institute of Palliative Care (ipac) e.V. (BMBF I6KT095I), Oldenburg, Germany

${ }^{3}$ Department of Palliative Medicine, Protestant Hospital Oldenburg, Oldenburg, Germany

${ }^{4}$ Clinic for Internal Medicine, Pius-Hospital Oldenburg, Oldenburg, Germany

${ }^{5}$ Oncological Practice Oldenburg, Oldenburg, Germany

${ }^{6}$ Department for Palliative Medicine, University Hospital Munich,

Munich, Germany
}

${ }^{7}$ Cicely Saunders Institute of Palliative Care, Policy \& RehabilitationWHO Collaborating Centre for Palliative Care and Older People, King's College London, London, UK

${ }^{8}$ Clinical Trials Unit (BMBF 0IKNII06), University Hospital of Cologne, Cologne, Germany

${ }^{9}$ Centre for Integrated Oncology (ClO) Köln Bonn, University Hospital of Cologne, Cologne, Germany

${ }^{10}$ Institute of Medical Statistics, Informatics and Epidemiology (IMSIE), University Hospital of Cologne, Cologne, Germany

Corresponding author:

Steffen T Simon, Department of Palliative Medicine, University Hospital of Cologne, Kerpener Str. 62, 50924 Cologne, Germany.

Email: steffen@steffensimon.de 


\section{What is already known about the topic?}

- Episodic breathlessness is one form of refractory breathlessness. It is a distressing and common symptom in advanced disease, but its characteristics have scarcely been described, yet. Clear information on the characteristics is necessary to enable effective management which is urgently needed for improving patients' quality of life.

\section{What this paper adds?}

- It adds information on the characteristics of 592 breathlessness episodes described by patients with advanced chronic obstructive pulmonary disease and lung cancer within a longitudinal cohort study. Breathlessness episodes are mainly described as severe, frequent (daily occurrence), and short (minutes only) with significant differences between the disease groups.

\section{Implications for practice, theory, or policy}

- Adequate management and coping strategies that correspond with the symptoms' characteristics, that is, the short duration, are urgently required to improve symptom relief and coping. In addition, the questions, what time span, what change in severity, or what other changes in the characteristics of episodic breathlessness mean a relevant difference for the patient should be addressed in future research.

\section{Introduction}

Refractory breathlessness (synonyms dyspn(o)ea, shortness of breath, or difficult breathing) is a complex and distressing symptom in advanced disease that persists despite optimal treatment of the underlying condition. ${ }^{1,2}$ Prevalence is up to $94 \%$ or $70 \%$ in patients with advanced chronic obstructive pulmonary disease (COPD) or lung cancer (LC), respectively. ${ }^{3-6}$ Experience may be continuous/chronic breathlessness (breathless all the time and at rest or with minimal exertion) or episodic breathlessness. ${ }^{7,8}$ Episodic breathlessness is defined as one form of breathlessness characterized by a severe worsening of breathlessness intensity or unpleasantness beyond usual fluctuations in the patient's perception. Episodes are timelimited (seconds to hours) and occur intermittently, with or without underlying continuous breathlessness. Episodes may be predictable or unpredictable, depending on whether any trigger(s) can be identified [...]. ${ }^{9}$

In 2009, Reddy et al. ${ }^{8}$ found that "breakthrough dyspnea" was the most frequent presentation of breathlessness $(81 \%)$ in a cohort of patients with advanced cancer which described breathlessness episodes as rather short but as interfering with patients' function and activity. Preliminary information on the characteristics of episodic breathlessness has also been explored in a crosssectional analysis of patients with different chronic diseases. ${ }^{10}$ Here, the majority of episodes were described as severe and lasting $10 \mathrm{~min}$ or less. Although empirical research on episodic breathlessness has increased over the most recent years, it had previously been rather neglected causing both a lack of understanding and insufficient management options. ${ }^{7-12}$ Therefore, the SYMPATIE cohort study was initiated to describe the courses of refractory breathlessness in patients with advanced COPD and LC. Data on the patterns of overall breathlessness severity, functional status, distress, and palliative care needs over time have been reported elsewhere. ${ }^{13}$ This article reports on the characteristics of episodic breathlessness and its patterns over the last year of life. Since the consensus definition of episodic breathlessness was established after the start of this study, we relied on the working definition of Reddy et al.: " a clinically significant aggravation of dyspnea in patients with continuous dyspnea or occurring intermittently."

\section{Methods}

\section{Study design}

This is a prospective, longitudinal cohort study. Ethical approval has been obtained from the State Medical Chamber of Lower Saxony, Hannover, Germany (Bo/20/2009). This article follows the STrengthening the Reporting of OBservational studies in Epidemiology (STROBE) guideline for cohort studies. ${ }^{14}$

\section{Participants and setting}

Patients aged $\geqslant 18$ years with COPD (Global Initiative for Chronic Obstructive Lung Disease (GOLD) classification stage III or IV) or primary LC (small cell LC (SCLC) or non-small cell LC (NSCLC) at any stage) were eligible. Patients received optimal treatment for their underlying condition as judged by the treating physician. Exclusion criteria were non-willingness or non-ability to provide written informed consent, poor physical condition not allowing assessment (judged by the treating physician), cognitive impairment (judged by the treating physician), or non-ability to speak German. 
Participants were recruited in two inpatient units (internal medicine) and two outpatient clinics in Oldenburg, Germany, by the treating physicians from February 2010 to April 2011.

\section{Data collection}

General information on the data collection procedures has been described in detail elsewhere. ${ }^{13}$ In short, data were collected at study entry (structured face-to-face interview at baseline) and then monthly ( $4 \pm 2$ weeks) by up to 13 structured follow-up telephone interviews. Baseline data included socio-demographics, diagnosis, spirometry, medication, functional status (Karnofsky Performance Status (KPS) scale ${ }^{15}$ ), and comorbidities (Charlson Comorbidity Index $\left.(\mathrm{CCI})^{16}\right)$.

In each interview, patients were asked whether episodic breathlessness had occurred. To explore the characteristics of episodic breathlessness, the following patient reported outcomes were assessed by two trained researchers. Peak severity was assessed by the modified Borg scale. ${ }^{17,18}$ Patients were asked to quantify the duration of episodes (in seconds, minutes, or hours). Frequency was evaluated by the categories: per day, per week, or less than per week, or alternatively: (1) 1-3/day, (2) 4-6/day, (3) 7-10/day, (4) 11-20/day, and (5) $>20 /$ day. Finally, patients were asked for the timing of their breathlessness episodes (during the day, at night, or both).

\section{Analysis}

Data were subsequently entered in a person-period dataset using EpiData 3.1 which provides programmed data entry and automatic error detection features. If patients used ranges (e.g. 5-10 min for the duration of episodes), means of the ranges were calculated and entered in the dataset. Electronic data were checked for correctness by a second researcher, and the final data were cleaned by a third researcher (screening for incomplete, implausible, or missing data and their correction, where appropriate). Analysis was conducted using SPSS Statistical Software for Windows, version 21 (SPSS, Inc.). We did not use imputation to replace missing data as we considered this inappropriate for our data.

For this analysis, the main outcomes were peak severity (modified Borg scale ${ }^{17,18}$ ), duration, frequency, and timing of breathlessness episodes. Therefore, only patients suffering from breathlessness episodes at least once during the study period were included in the analysis.

Descriptive analysis was conducted for baseline and longitudinal data (percentage, mean, standard deviation (SD), 95\% confidence interval (CI), median, and range), comparing all outcomes between the disease groups. According to the Borg scale descriptions, breathlessness was defined as severe for scores $\geqslant 5 .{ }^{17,18}$ Categories for the duration and frequency were created post hoc based on the data.

The main outcomes were analyzed as follows:

1. The main analysis was based on the unit "breathlessness episode." For this, data on the outcomes of each episode described during any interview over the study time were pooled and analyzed using descriptive statistics. To consider repeated measurement in individuals, the patient was also considered as unit of analysis. By calculating means or medians for the available data on the characteristics of episodes per patient, an average profile of the breathlessness episodes per patient was achieved. The aggregated data were also analyzed using descriptive statistics.

2. The relationship between the characteristics of episodes was explored using correlation analysis. First, bivariate correlation coefficients (r) were calculated for each patient over each point of measurement; second, means of these values were computed separately for COPD and LC patients. One-sample t-tests were used to test the difference of these values versus 0 ; two-sample t-test was used to compare outcomes between the disease groups.

3. For patients who died, the patterns of outcomes were explored over the last 365 days before death.

To test for differences in continuous data, independent t-test or Mann-Whitney U-test was applied as appropriate (approximately normally or not normally distributed data, respectively). Categorical data were compared using chisquare test or Fisher's exact test, as appropriate.

Because this study was of descriptive rather than confirmatory character, the level of significance was set to $p<0.05$, two-sided for all analyses.

\section{Results}

\section{Study population}

A total of 82 (50 COPD, 32 LC) patients were included in the analysis (Table 1). Median study duration tended to be longer in COPD than in LC patients (178 days (range $=1-$ 393 days) vs 151 days ( $0-386$ days), $p=0.071)$. A total of 34 patients $(42 \%$; 26 COPD, 8 LC) completed maximum data collection of 13 interviews (for numbers per followup interview, see Table 2 (online supplement)). A total of 13 patients (3 COPD, $10 \mathrm{LC}$ ) died during the data collection phase (total deaths: 8 COPD and 23 LC patients before final subsequent collection (5 September 2012), see also Weingärtner et al. ${ }^{13}$ ). A total of 35 patients (21 COPD, 14 LC) did not finish the 12-month period of data collection due to other reasons than death (15 worsening of medical 
Table I. Patient characteristics.

\begin{tabular}{|c|c|c|c|c|c|c|}
\hline \multirow[t]{3}{*}{ Number of patients } & \multirow{2}{*}{$\begin{array}{l}\text { Total } \\
\mathrm{n}(\%)\end{array}$} & \multicolumn{2}{|l|}{ COPD } & \multicolumn{2}{|l|}{$\mathrm{LC}^{\mathrm{a}}$} & \multirow{3}{*}{$\begin{array}{l}\text { Difference } \\
\text { (p-value) }\end{array}$} \\
\hline & & \multicolumn{2}{|l|}{ n (\%) } & \multicolumn{2}{|l|}{ n (\%) } & \\
\hline & $82(100)$ & $50(100$ & & $32(100)$ & & \\
\hline \multicolumn{7}{|l|}{ Socio-demographic details } \\
\hline Age (years), mean (SD) & $67.2(7.8)$ & $67.7(7$. & & $66.4(8.2)$ & & 0.472 \\
\hline Female, n (\%) & $30(37)$ & 21 & & $9(28)$ & & 0.203 \\
\hline \multicolumn{7}{|l|}{ Smoking $(M D=2)$} \\
\hline Never & $7(9)$ & $3(6)$ & & $4(13)$ & & 0.317 \\
\hline Former & $63(77)$ & $39(78$ & & $24(75)$ & & \\
\hline Still & $10(12)$ & $8(1$ & & $2(6)$ & & \\
\hline \multicolumn{7}{|l|}{ Clinical characteristics } \\
\hline $\mathrm{CCl}$, median (range) & $1.0(0-11)$ & $1.0(0$ & & $2.0(0-11)$ & & 0.150 \\
\hline KPS, mean (SD) & $73.5(14.9)$ & $69.4(1 / 2$ & & $80.0(13.7)$ & & 0.001 \\
\hline Suppl. Oxygen, n (\%) & $31(38)$ & $27(5$ & & $4(13)$ & & $<\mathbf{0 . 0 0 1}$ \\
\hline \multirow[t]{12}{*}{ Disease-specific details } & & GOLD & n (\%) & TNM & n (\%) & \\
\hline & & III & $20(40)$ & Illa & $4(12.5)$ & \\
\hline & & IV & $30(60)$ & Illb & $3(9.4)$ & \\
\hline & & & & IV & $22(68.7)$ & \\
\hline & & & & MD & $3(9.4)$ & \\
\hline & & $\mathrm{FEV}, \%$ & Mean (SD) & Metastases $^{\mathrm{b}}$ & $\mathrm{n}$ & \\
\hline & & & $32.1(11.6)$ & Lymph node & II & \\
\hline & & & & Pulmonary & 15 & \\
\hline & & & & Cerebral & 4 & \\
\hline & & & & Liver & 4 & \\
\hline & & & & Bone & 13 & \\
\hline & & & & Pleura & 5 & \\
\hline
\end{tabular}

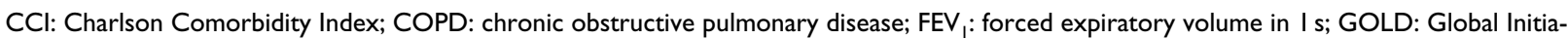
tive for Chronic Obstructive Lung Disease; KPS: Karnofsky Performance Status; LC: lung cancer; MD: missing data; SD: standard deviation; TNM: tumor-nodes-metastases classification; SCLC: small cell lung cancer; NSCLC: non-small cell lung cancer.

Bold $p$-values indicate statistical significance.

aSCLC: $n=4$, NSCLC: $n=28$; two lung cancer patients also had a diagnosis of COPD.

bMultiple answers possible.

condition and/or hospital stay, 13 unavailable for more than 6 weeks, 4 loss of interest, 2 illness or death of relative, and 1 "feeling too healthy"). ${ }^{13}$

\section{Characteristics of all breathlessness episodes described}

Episodic breathlessness was reported at all interviews in $58(71 \%)$ patients. Occurrence at all interviews was more often reported in COPD compared to LC patients (40 $(80 \%)$ vs $18(56 \%) ; p=0.021)$. In each interview over time, $81 \%-97 \%$ of patients with COPD and $75 \%-88 \%$ of patients with LC reported breathlessness episodes (data per interview provided in Table 2 (online supplement)).
In total, the cohort reported 592 breathlessness episodes (COPD: 403, LC: 189) during the study (Table 3). One COPD patient reported the occurrence of breathlessness episodes only once during data collection but was not able to describe its characteristics. Similarly, two LC patients could not determine the frequency of their episodes. Peak severity of episodes described by COPD patients was higher than in LC patients $(p<0.001)$, and correspondingly, severe scores $(\geqslant 5)$ were more often reported in COPD patients $(p<0.001)$.

Median duration of episodes described by COPD patients was $2 \mathrm{~min}$ longer than of episodes reported by LC patients ( $p=0.002$; Table 3$)$. Although most episodes were described as lasting $20 \mathrm{~min}$ or less, some episodes were 
Table 3. Characteristics of breathlessness episodes as described by the cohort.

\begin{tabular}{|c|c|c|c|c|}
\hline & Total & COPD & LC & Difference ( $p$-value) \\
\hline & n (\%) & n (\%) & n (\%) & \\
\hline Total number of episodes, $\mathrm{n}(\%)$ & $592(100)$ & $403(100)$ & $189(100)$ & $<\mathbf{0 . 0 0 I}$ \\
\hline Peak severitya, valid $n$ & 589 & 400 & 189 & \\
\hline Mean (SD) Borg score & $5.6(2.3)$ & $6.2(2.1)$ & $4.2(1.9)$ & $<\mathbf{0 . 0 0 I}$ \\
\hline Severe scores $(\geqslant 5), \mathrm{n}(\%)$ & $374(63.5)$ & $311(77.8)$ & $63(33.3)$ & $<\mathbf{0 . 0 0 1}$ \\
\hline Average duration ${ }^{b}$, valid $n$ & 576 & 392 & 184 & \\
\hline Median (range), min & $5.0(0.02-600)$ & $7.0(0.02-600)$ & $5.0(0.3-120)$ & 0.002 \\
\hline$\leqslant 5 \min , \mathrm{n}(\%)$ cumulative & $303(52.6)$ & $188(50.0)$ & $115(62.5)$ & 0.001 \\
\hline$\leqslant 10 \min , \mathrm{n}(\%)$ cumulative & $4 \mid 4(7 \mid .9)$ & $267(68.1)$ & 147 (79.9) & 0.003 \\
\hline$\leqslant 20 \min , \mathrm{n}(\%)$ cumulative & $515(89.4)$ & $339(86.5)$ & $176(95.7)$ & 0.001 \\
\hline$\leqslant 30 \min , \mathrm{n}(\%)$ cumulative & $546(94.8)$ & $366(93.4)$ & $180(97.8)$ & 0.025 \\
\hline$\leqslant 60 \mathrm{~min}, \mathrm{n}(\%)$ cumulative & $563(97.7)$ & $381(97.2)$ & $182(98.9)$ & 0.196 \\
\hline$\leqslant 120$ min, $\mathrm{n}(\%)$ cumulative & $569(98.8)$ & $385(98.2)$ & $184(100.0)$ & 0.103 \\
\hline$\leqslant 600$ min, $n(\%)$ cumulative & $576(100.0)$ & $392(100.0)$ & $184(100.0)$ & - \\
\hline Frequency ${ }^{c, d}$, valid $n$ & 546 & 373 & 173 & \\
\hline$>3$ per day & $123(22.5)$ & $90(24.1)$ & $33(19.1)$ & 0.342 \\
\hline I-3 per day & $274(50.2)$ & 178 (47.7) & $96(55.5)$ & \\
\hline Weekly & I $44(26.4)$ & $102(27.3)$ & $42(24.3)$ & \\
\hline Less than weekly & $5(0.9)$ & $3(0.8)$ & $2(1.2)$ & \\
\hline Timing, valid n (\%) & 589 & 400 & 189 & \\
\hline Solely during the day & $479(81.3)$ & $296(74.0)$ & $183(96.8)$ & $<\mathbf{0 . 0 0 I}$ \\
\hline At night only or both & $110(18.7)$ & $104(26.0)$ & $6(3.2)$ & \\
\hline
\end{tabular}

COPD: chronic obstructive pulmonary disease; LC: lung cancer; MD: missing data; SD: standard deviation.

Numbers and percentages are presented if not stated otherwise. Bold $p$-values indicate statistical significance.

$\mathrm{aMD}=3$.

${ }^{b}$ Determination of duration was not possible for patients in 12 episodes (COPD 7, LC 5); MD = 4.

'Original categories were summed as presented.

dDetermination of frequency was not possible for patients in 14 episodes (COPD 8, LC 6); MD = 32.

reported as lasting only a few seconds, and some episodes were said to last for hours (Figure 1).

Summed categories for the frequency of episodes were created based on the data (Table 3). Frequency of episodes was similar in both groups and most often described as being a daily occurrence and even several times a day (397 (73\%); COPD: 268 (72\%), LC: 129 (75\%); $p=0.507)$ ).

Most episodes occurred during the day. Nighttime episodes occurred more often in the COPD group than in the LC group (Table 3).

Based on patients as unit of analysis, the results on the characteristics of breathlessness episodes did not differ from these findings. There was great variation in the characteristics both between and within the individuals at different assessment points, respectively.

\section{Backward analysis: patterns of episodes described in the last year of life}

A total of 30 (8 COPD, 22 LC) of the 31 patients who died before subsequent assessment provided data within their last 365 days of life. Episodes were predominantly described as lasting less than $30 \mathrm{~min}$ in the COPD group and less than $20 \mathrm{~min}$ in the LC group (Figure 2(a)). Of note, breathlessness episodes lasting longer than $30 \mathrm{~min}$ were described only four times by LC patients who died and predominantly occurred when they were in their last days of life. Moreover, these episodes were all described as severe $(\geqslant 5)$ (Figure 2(b)). Although the descriptions of episodes in COPD patients were on average more severe than those of LC patients, severity differed strongly between the single episodes described within both disease groups (Figure 2(b)).

\section{Correlation analysis}

The peak severity was positively correlated with the frequency of episodes described by LC patients (mean $\mathrm{r}=0.324, p=0.009 ; p$ difference $=0.028$ ) but not COPD patients (Table 4). No further associations between the characteristics were statistically significant.

\section{Discussion}

This is the first study comparing longitudinal data on the self-assessed characteristics of episodic breathlessness in 


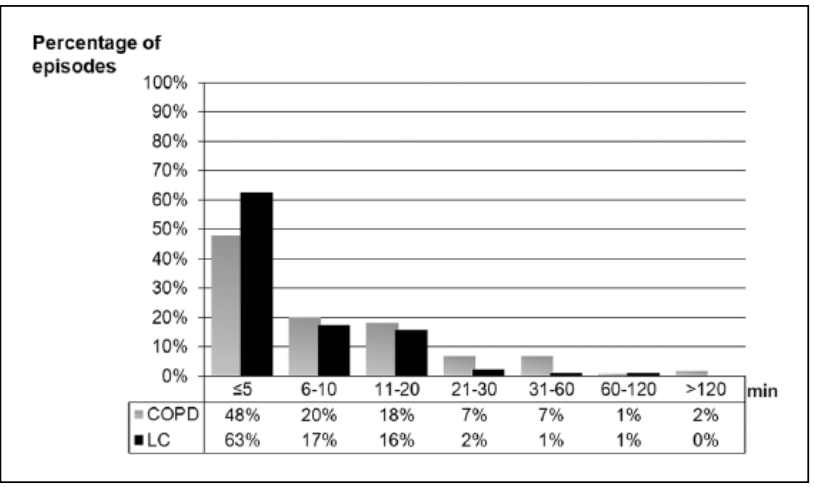

Figure I. Distribution of the average duration of breathlessness episodes. The graph shows the percentage of breathlessness episodes per duration (minutes) described by patients in each disease group.

COPD: chronic obstructive pulmonary disease; LC: lung cancer.

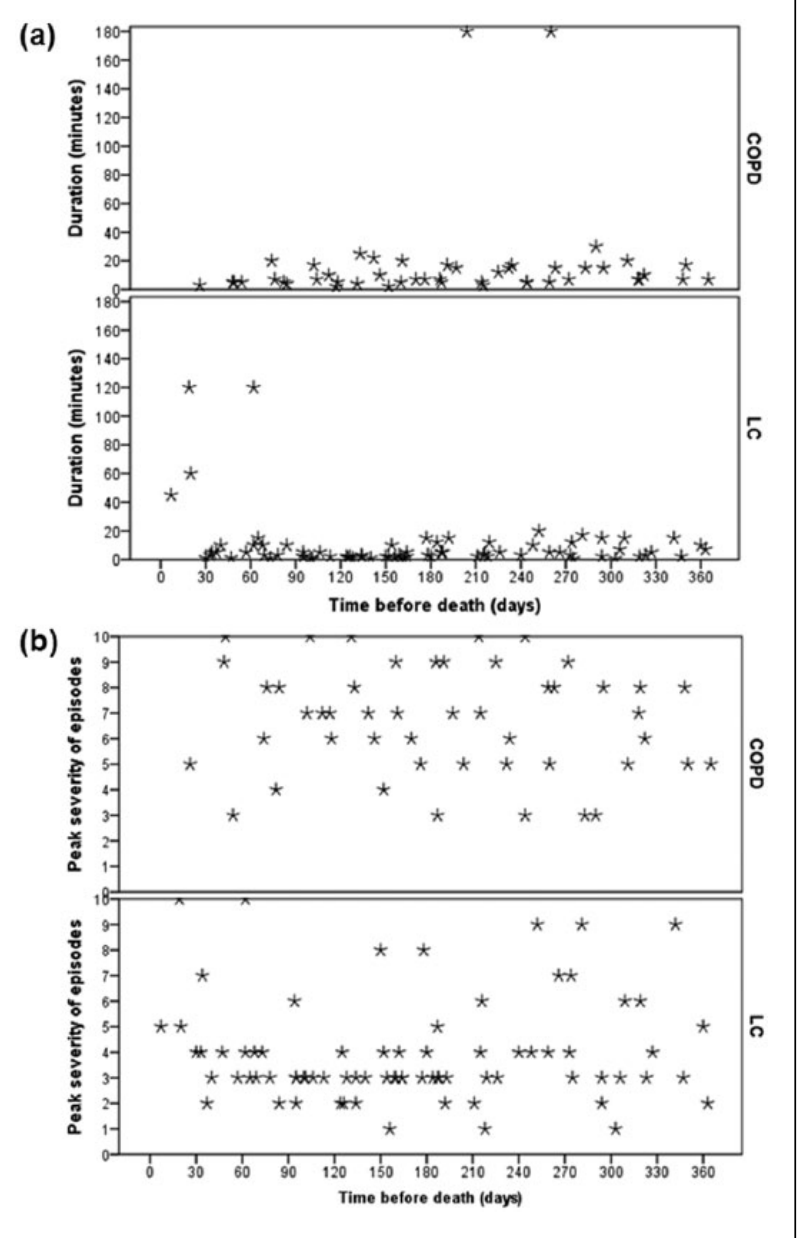

Figure 2. (a) The duration (minutes) of breathlessness episodes as described by decedents in each disease group within their last 365 days of life. (b) The severity of breathlessness episodes (modified Borg scale: $0-10$ ) as described by decedents in each disease group within their last 365 days of life. COPD: chronic obstructive pulmonary disease; LC: lung cancer.
Table 4. Mean Pearson correlations of the characteristics of breathlessness episodes described.

\begin{tabular}{llllll}
\hline & COPD & $p^{\mathrm{a}}$ & LC & $p^{\mathrm{a}}$ & $p$ difference $^{\mathrm{b}}$ \\
\hline $\begin{array}{l}\text { Peak severity- } \\
\text { duration }\end{array}$ & -0.032 & 0.679 & 0.057 & 0.653 & 0.527 \\
$\begin{array}{l}\text { Peak severity- } \\
\text { frequency }\end{array}$ & 0.011 & 0.892 & 0.324 & $\mathbf{0 . 0 0 9}$ & $\mathbf{0 . 0 2 8}$ \\
$\begin{array}{l}\text { Duration- } \\
\text { frequency }\end{array}$ & -0.037 & 0.630 & -0.055 & 0.636 & 0.900 \\
\hline
\end{tabular}

COPD: chronic obstructive pulmonary disease; LC: lung cancer. Bold $p$-values indicate statistical significance.

${ }^{a}$ Difference to 0 (one-sample t-test, $\alpha=0.05$ ).

bDifference between COPD and LC patients (two-sample t-test, $\alpha=0.05)$.

patients with different underlying diseases. Patients with COPD perceived breathlessness episodes as severe, and peak severity was significantly higher than that described by LC patients. Breathlessness episodes were predominantly described as short in both groups, that is, lasting only minutes. However, the duration of episodes described by COPD patients was slightly longer compared to episodes described by LC patients. Episodes occurred mainly daily in both groups although there was fluctuation between groups and within individual patients.

These findings underline the burden of episodic breathlessness (high severity and frequency) and the challenge regarding its management (short duration). Disease-specific, needs-based care for patients with COPD and LC suffering from episodic breathlessness is needed, and effective management and coping options are still warranted.

\section{Interpretation of main findings}

Although the assessment of duration, severity, and frequency must be considered as explorative and the patients' retrospective assessment of their breathlessness episodes may be subject to recall bias, our results are in line with previous cross-sectional research and provide important information on the characteristic manifestation of this distressing symptom..$^{8,10,11,19,20}$ In another study by our group evaluating a mixed population of 129 patients with COPD, LC, chronic heart failure (CHF), or motor neuron disease (MND), the duration of episodes described was 10 or 20 min maximal in $75 \%$ or $91 \%$, respectively. ${ }^{10}$ In the observational study of Reddy et al., ${ }^{8} 50$ of 57 (87\%) cancer patients reported episodes of $10 \mathrm{~min}$ maximum. In two qualitative studies, LC patients predominantly reported the duration of 5-15 min..$^{20,21}$ Finally, Maddocks et al..$^{19}$ found a median recovery time of only $4 \mathrm{~min}$ particularly for exercise-induced breathlessness in LC patients based on realtime measurement. These data support our findings on both the short duration of episodes in general and the significantly shorter duration in the cancer compared to the non-cancer group. 
The high severity of breathlessness episodes in COPD patients is supported by the findings of Heinzer et al.,22 reporting a mean severity of 7/10 (Borg) in 41 COPD inpatients. Reddy et al. ${ }^{8}$ found a median severity of $5 / 10$ (Numerical Rating Scale (NRS)) for cancer patients, which is slightly higher than in our cohort particularly with LC patients. However, the differences are small and may be due to the different measurement instruments.

The revealed significant differences between COPD and LC patients' episodes are in contrast to a previous study by our group comparing the characteristics of breathlessness episodes between diverse disease groups. ${ }^{10}$ Considering the higher number of episodes analyzed in this study and the results of the studies on single entities mentioned above, it may be possible that the breathlessness episodes experienced by COPD patients differ from those experienced in LC patients. However, there is yet no evidence about the relevance of these differences in the characteristics of episodic breathlessness for the patients.

\section{Implications for clinical practice}

Today, the differentiation of chronic and breakthrough pain is well established in clinical practice and substantially considered for effective management. ${ }^{23-26}$ Similarly, the differentiation of continuous and episodic breathlessness is increasingly recognized as being relevant for effective symptom relief., 27 Based on our findings, breathlessness episodes might be even shorter than pain episodes which last a median duration of $30-60 \mathrm{~min} .^{26,28,29}$

Currently, immediate-released morphine (IRM) is the standard pharmacological treatment for episodic breathlessness. In studies of pain, IRM showed an onset of action after $20-30 \mathrm{~min} .{ }^{30}$ Our findings indicate that the duration of the vast majority of breathlessness episodes is much shorter, and therefore, IRM might be inadequate. However, the data of onset of action for IRM come from pain studies, and the onset of action for breathlessness is yet unknown. An ongoing study by our group is currently evaluating the onset of action of opioids (including IRM) for breathlessness and will hopefully provide this relevant information (EudraCT Number: 2011-005797-32). Moreover, even fast-acting drugs, for example, fentanyl, might not effectively relieve these short breathlessness episodes. However, these drugs may still be a preventive option for predictable episodes, for example, exertioninduced breathlessness.

\section{Implications for future research}

One major finding of this study is the predominantly short duration of episodes of breathlessness which poses a challenge for its management and particularly for pharmacological options as the onset of action of most drugs in use takes longer than the majority of episodes last.
The recently established categorization into predictable or unpredictable episodes, depending on whether any trigger(s) can be identified (e.g. exertion, emotions, or external factors), might be an explanation for the significant variance within and between patients' perceptions of breathlessness episodes in this study. ${ }^{7,9}$ The distinction between episodic breathlessness categories needs to be assessed in future research.

Existing studies suggest substantial effects of episodic breathlessness on the quality of life of both patients and their relatives. ${ }^{8,12,31}$ However, the most relevant characteristics (severity, frequency, duration, predictability, and concurring emotions) which affect patients most and should be top priority for management strategies remain unknown and need to be determined - including the minimal clinical important differences.

Clinical research evaluating the effectiveness of fastacting drugs and non-pharmacological options, such as psychological and cognitive strategies for the palliation of episodic breathlessness, is still rare. Moreover, data on coping strategies are scare and should be assessed by affected patients and relatives based on the established international definition and categorization. ${ }^{9}$

Clarifying the consequences of the symptom and related needs will further facilitate improvement in health-care provision and patients' quality of life. Finally, it seems relevant to examine whether different manifestations of breathlessness are related to death and whether specific treatments or care are required with nearing death or, contrarily, should then be omitted.

\section{Limitations}

The number of patients included was smaller than originally planned, and several participants dropped out due to a deterioration of their overall health condition. This confirms the advanced stage of diseases but limited the use of more in-depth statistical analysis. The results and statistical tests have to be interpreted solely descriptively. The overall condition and cognitive status of patients were evaluated as criteria for inclusion by the treating physician without the use of objective measures, which might be judged as a limitation for replication.

There is a possibility of recall bias since patients reported their episodes retrospectively. However, recent data support our findings on the characteristics of breathlessness episodes. ${ }^{8}, 10,11,19$

Due to the small number of patients providing data for each point in time before death, we decided to conduct backward analysis only exploratively and without statistical testing. In particular, the patterns of the characteristics shortly before death should be addressed further in future research.

Patients had received optimal treatment of their underlying condition at baseline. However, this was not assessed at follow-ups. Similarly, concomitant medication were 
allowed but only assessed at baseline and not considered for the analysis. The impact of both treatment and additional medications on episodic breathlessness should be addressed in future research.

Finally, after conducting this study, the amended definition and categorization of episodic breathlessness have been established. ${ }^{9}$ However, the new definition does not conflict but only further specifies the previous definition of Reddy et al. ${ }^{8}$

\section{Conclusion}

Episodes of breathlessness perceived by patients with COPD differ from episodes perceived by patients with LC by a higher severity and longer duration; however, duration was short (minutes) in both disease groups. More research is required to describe and compare the specific causes, care needs, and therapeutic targets of patients with predictable or unpredictable episodes of breathlessness and differences between disease groups, respectively.

Since the onset of action of most drugs in use is longer than breathlessness episodes usually last, effective nonpharmacological management alternatives that adapt to the short duration of episodes and coping strategies are urgently warranted in order to relieve symptom suffering and to improve quality of life in affected patients.

\section{Acknowledgements}

The results of this study were presented as oral presentations at the 8th World Research Congress of the European Association for Palliative Care (EAPC) (5-7 June 2014, Lleida, Spain) and at the 10th Congress of the German Association of Palliative Medicine (24-27 June 2014, Düsseldorf, Germany). We would like to thank all participants of this survey for their support in conducting this study. Thanks to the members of the PAALiativ project group: Birgit Kannenberg-Otremba, Nicole Sowinsky, Alexander Jüptner, Jochen Meyer, Julia Cortis, Andreas WagnerNeidig, Andreas Hein, Dietmar Reichert, Marion Jessen, Melina Frenken, and Thomas Frenken. We would also like to thank Kathrin Kuhr from the Institute of Medical Statistics, Informatics and Epidemiology (IMSIE), University Hospital of Cologne for additional statistical advice and Heather Graham for her support in proofreading as a native speaker.

\section{Declaration of conflicting interests}

S.T.S. and R.V. received research funding for a clinical trial from TEVA Ltd. V.W. received reimbursement of travel costs from Teva GmbH for the 8th World Research Congress of the European Association of Palliative Care (Lleida, Spain). All other authors declare that there are no conflicts of interest.

\section{Funding}

The SYMPATIE study is part of the PAAliativ project which is funded by the German Federal Ministry of Education and Research (BMBF 16KT0951). The Department of Palliative Medicine, University Hospital of Cologne, is supported by German Cancer
Aid (Deutsche Krebshilfe e.V.) as well as by the Federal Ministry of Education and Research (BMBF 01KN0706).

\section{References}

1. Booth S, Bausewein C, Higginson I, et al. Pharmacological treatment of refractory breathlessness. Expert Rev Respir Med 2009; 3: 21-36.

2. Dorman S, Jolley C, Abernethy A, et al. Researching breathlessness in palliative care: consensus statement of the National Cancer Research Institute Palliative Care Breathlessness Subgroup. Palliat Med 2009; 23: 213-227.

3. Alt-Epping B, Staritz AE, Simon ST, et al. What is special about patients with lung cancer and pulmonary metastases in palliative care? Results from a nationwide survey. $J$ Palliat Med 2012; 15: 971-977.

4. Blinderman CD, Homel P, Billings JA, et al. Symptom distress and quality of life in patients with advanced chronic obstructive pulmonary disease. J Pain Symptom Manage 2009; 38: 115-123.

5. Currow DC, Smith J, Davidson PM, et al. Do the trajectories of dyspnea differ in prevalence and intensity by diagnosis at the end of life? A consecutive cohort study. J Pain Symptom Manage 2010; 39: 680-690.

6. Moens K, Higginson IJ and Harding R. Are there differences in the prevalence of palliative care-related problems in people living with advanced cancer and eight non-cancer conditions? A systematic review. J Pain Symptom Manage 2014; 48: 660-677.

7. Simon ST, Higginson IJ, Benalia H, et al. Episodic and continuous breathlessness: a new categorization of breathlessness. J Pain Symptom Manage 2012; 45: 1019-1029.

8. Reddy SK, Parsons HA, Elsayem A, et al. Characteristics and correlates of dyspnea in patients with advanced cancer. J Palliat Med 2009; 12: 29-36.

9. Simon ST, Weingärtner V, Higginson IJ, et al. Definition, categorization, and terminology of episodic breathlessness: consensus by an international Delphi survey. J Pain Symptom Manage 2014; 47: 828-838.

10. Weingärtner $\mathrm{V}$, Bausewein $\mathrm{C}$, Higginson $\mathrm{IJ}$, et al. Characterizing episodic breathlessness in patients with advanced disease. J Palliat Med 2013; 16: 1275-1279.

11. Simon ST, Bausewein C, Schildmann E, et al. Episodic breathlessness in patients with advanced disease: a systematic review. J Pain Symptom Manage 2013; 45: 561-578.

12. Simon ST, Higginson IJ, Benalia H, et al. Episodes of breathlessness: types and patterns - a qualitative study exploring experiences of patients with advanced diseases. Palliat Med 2013; 27: 524-532.

13. Weingärtner V, Scheve C, Gerdes V, et al. Breathlessness, functional status, distress and palliative care needs over time in patients with advanced chronic obstructive pulmonary disease or lung cancer: a cohort study. J Pain Symptom Manage 2014; 48: 569-581.e1.

14. Von Elm E, Altman DG, Egger M, et al. Strengthening the Reporting of Observational Studies in Epidemiology (STROBE) statement: guidelines for reporting observational studies. BMJ 2007; 335: 806-808.

15. Yates JW, Chalmer B and McKegney FP. Evaluation of patients with advanced cancer using the Karnofsky performance status. Cancer 1980; 45: 2220-2224. 
16. Charlson ME, Pompei P, Ales KL, et al. A new method of classifying prognostic comorbidity in longitudinal studies: development and validation. J Chronic Dis 1987; 40: 373-383.

17. Burdon JG, Juniper EF, Killian KJ, et al. The perception of breathlessness in asthma. Am Rev Respir Dis 1982; 126: $825-828$.

18. Van der Molen B. Dyspnoea: a study of measurement instruments for the assessment of dyspnoea and their application for patients with advanced cancer. $J A d v$ Nurs 1995; 22: 948-956.

19. Maddocks M, Taylor V, Klezlova R, et al. When will I get my breath back? Recovery time of exercise-induced breathlessness in patients with thoracic cancer. Lung Cancer 2012; 76: 128-129.

20. O'Driscoll M, Corner J and Bailey C. The experience of breathlessness in lung cancer. Eur J Cancer Care 1999; 8: 37-43.

21. Lai YL, Chan CW and Lopez V. Perceptions of dyspnea and helpful interventions during the advanced stage of lung cancer: Chinese patients' perspectives. Cancer Nurs 2007; 30: E1-E8.

22. Heinzer MM, Bish C and Detwiler R. Acute dyspnea as perceived by patients with chronic obstructive pulmonary disease. Clin Nurs Res 2003; 12: 85-101.

23. Portenoy RK and Hagen NA. Breakthrough pain: definition, prevalence and characteristics. Pain 1990; 41: 273-281.

24. Davies AN, Dickman A, Reid C, et al. The management of cancer-related breakthrough pain: recommendations of a task group of the Science Committee of the Association for Palliative Medicine of Great Britain and Ireland. Eur J Pain 2009; 13: 331-338.

25. Caraceni A, Davies A, Poulain P, et al. Guidelines for the management of breakthrough pain in patients with cancer. $J$ Natl Compr Canc Netw 2013; 11(Suppl. 1): S29-S36.

26. Davies A, Buchanan A, Zeppetella G, et al. Breakthrough cancer pain: an observational study of 1000 European oncology patients. J Pain Symptom Manage 2013; 46: 619-628.

27. Johnson MJ, Abernethy AP and Currow DC. Gaps in the evidence base of opioids for refractory breathlessness. A future work plan? J Pain Symptom Manage 2012; 43: 614-624.

28. Davies A, Zeppetella G, Andersen S, et al. Multi-centre European study of breakthrough cancer pain: pain characteristics and patient perceptions of current and potential management strategies. Eur J Pain 2011; 15: 756-763.

29. Portenoy RK, Payne D and Jacobsen P. Breakthrough pain: characteristics and impact in patients with cancer pain. Pain 1999; 81: 129-134.

30. Freye E, Levy JV and Braun D. Effervescent morphine results in faster relief of breakthrough pain in patients compared to immediate release morphine sulfate tablet. Pain Pract 2007; 7: 324-331.

31. Giacomini M, DeJean D, Simeonov D, et al. Experiences of living and dying with COPD: a systematic review and synthesis of the qualitative empirical literature. Ont Health Technol Assess Ser 2012; 12: 1-47. 